\title{
The study of lineage and privacy of the child resulting from gamete and embryo donation in Islamic jurisprudence and Iranian law
}

\author{
Mohammad Moradi ${ }^{*}$, Ehsan Heydari Motlagh \\ Department of Private Law, Islamic Azad University, Sirjan Branch, Iran
}

Email address:

mlamoradi@yahoo.com (M. Moradi)

\section{To cite this article:}

Mohammad Moradi, Ehsan Heydari Motlagh. The Study of Lineage and Privacy of the Child Resulting from Gamete and Embryo Donation in Islamic Jurisprudence and Iranian Law. Social Sciences. Vol. 3, No. 5, 2014, pp. 144-152. doi: 10.11648/j.ss.20140305.11

\begin{abstract}
The embryo donation has been studied by many scientists and practitioners after the approval of the act of the embryo donation to infertile couples in 1382. The main question posed here is concerned with the lineage and intimacy status of this donation for the child and also "to whom does the child belong"? To answer this question this result was obtained that in Iranian law, the complete assignment of the child to the applicant couple has not been accepted. Iranian law is also silent on lineage field. But from jurisprudents point of view and regarding verses and traditions, the child's original parents are the owners of ovule and sperm and also about the lineage of the owner of uterus, she is the child's "consented" mother. If the child is a girl as she is served as the father's stepdaughter, he would be confident to the child. The objective of this study was to clarify the child lineage induced by embryo donation with donors and receivers in Iranian law. To write this thesis, a library method has been used. At the end of the writing some recommendations have been proposed that are useful to solve some of the present and future problems.
\end{abstract}

Keywords: Confidence, Embryo Donation, Lineage, Recommendation, Respect or Permit

\section{Introduction}

The human creation story is so complex, wonderful and mysterious. According to the saint books especially Quran, the main essence of the man is soil to which God granted spirit and life. Many years ago, when there were no significant advances in medicine, there was not possible to distinguish which parent was incapable of fertilization, but regarding the patriarchy culture dominated on the societies, they often related it to the woman so the first treatment prescription to have a baby was the husband remarriage. By this, a baby could be born of another woman and the woman incapable of fertilization was responsible for raising that child.

In recent years the medical knowledge has offered some solutions to solve such problems. But after solving these problems, some new problems have emerged that no longer could be solved by doctors. Making a decision was necessary here. To do so, some researches should have been performed on these new methods to treat infertility to characterize and confirm its different aspects. Many scholars, jurisprudents and professors wrote many books and articles to examine various aspects of this topic (Ghasemzadeh, 2007; Merghati, 2007).
Donating gamete and embryo are new and successful forms of infertility treatments that bring hope for couples. It was thought previously that they could never have children. This method usually has less cost and medical complications than IVF methods and it serves as the most significant achievements during this century. Nevertheless, donating sperm, ovule and embryo is a challenging topic legally and morally. The law has not mentioned the lineage and relations of these persons and there are some ambiguities in this field.

\section{The Original Assignment of the Child to Father}

\subsection{Custom View}

Medically, the origin of the embryo formed by father is the sperm in human semen and there is no doubt about it (Akhondi, Ardakani, \& Arefi, 2006). On the other hand, the common custom also considers that the measure of lineage between two persons is one emerging of the other, not just birth, so to express this actual event a title calls "lineage" has been abstracted. Totally, the law has also commented that one 
emerges from the other, but it restricted the way of emergence for some reasons. Now this question arises that if some approaches are presented which do reproduction within the law framework, merely because they have no background in law and they had not been thoroughly clarified by legislators, should they be recognized as formal?

\subsection{The Quran and Tradition Viewpoints}

The holy Quran has expressed the origin of man creation and lineage measure using a very good interpretation:

And he is who that created a man from a liquid and set relatives for him. Two possibilities have been considered in the word "liquid":

1. Absolute of liquid; means the origin of the living thing emergence is the absolute of liquid.

2. Sperm, means that man has been created from sperm (Tabatabaie, 1996).

Here, two very subtle points are implied in the verse: first, the origin and constituent of human is expressed by "creation" interpretation (means formation and invention that is God's exclusive attribute), as the lineage with the "set" interpretation (means to transform one thing on a special state that can be an attribute for a non-God) on the word "man" has been resulted. Thus the two interpretations "creation" and "set" altogether and in a same verse points to the difference in their meaning. Another remark is that the term "recreation" is used that is just the man created from liquid who has lineage and his lineage is a reliable and a transformed state of liquid "sperm" and it doesn't originate from another thing, but stating the man's creation origin, the lineage can be validated and explained. In tradition, just this meaning has been clarified (Hore Ameli, 2000).

Therefore, the interpreted concepts from Quran and traditions are just the custom interpretations and this is reliable upon Islamic law such as civil law. Thus the matrilineal is a reliable lineage that is abstracted from the child born by another person's sperm.

\section{The Origin Assignment of Child to Mother}

Law has not presented a certain definition of metronymic. As a result regarding the article 167 of constitutional law, we refer to the Islamic validated sources to examine metronymic.

About the measure of the child emergence from mother, some jurisprudences and lawyers consider the childbirth as a measure to assign the child to the mother; some others (Mohagheghdamad, 1998) say that: two elements affect the child emergence: first, the child emergence from sperm and the other child carrying and his delivery by mother. Mother has these two elements and the third group considers the assignment measure the child emergence from woman ovule.

Custom derives a title from the genetic lineage of the child with the sperm and owner of ovule calls "lineage". By this definition, no longer the term lineage serves as a mere contractual validity to legislate law, not only to separate person lineage from his genetic origin but also to prove that this title has a natural, actual and evolutional origin. Since the legislator has not denied the lineage and its effects and just considers the adultery as the only example of illegal lineage, it is essential to examine this issue. Solving it other lineages result from non-adultery approaches can be solved.

\subsection{The Concept of Adultery in Lineage}

The basic question in this section is that "what is the measure to distinguish lineage from the Islamic legislator point of view and follow that in Iran? Does every baby who named child legally and lexically has this description in religion too (until it is not from adultery) or lineage? If it serves reliable which has legal reason and if it is not results from the correct marriage or doubtless intercourse, can it be served illegal and unreliable? Civil law not presenting any definition of the adultery concept, states that:" the baby born from adultery is not assigned to the libertine "and the Islamic penalty law in article 63 appointed that "adultery means the man copulate with a woman who is illegal to him in essence, though it is in contrive, in cases other than Wada to doubt". On the one hand, this definition in law is stated below the adultery penance title, so it relates to the penance adultery and on the other hand the definition itself has application so it includes non-penance adultery.

Whereby, this question arises that "is the concept of adultery in lineage the same as its concept in adultery penance and does it include some cases such as man intercourse with alien woman, then semen ejaculation and its absorption by uterus, offload semen to the alien woman uterus, the alien man sperm inoculation to the alien woman uterus and so on?

The term adultery is one of the custom concepts for which no religious reality and new establishment has been proved. Looking attentively in this tradition and other ones and also regarding the rules result from their topics titles, it can conclude that the concept of adultery is not a brief one and besides jurisprudents have no new term about lineage results from adultery, but also they have emphasized that by adultery they mean the intercourse with specific conditions in that given limits.

Thus the concept of adultery in lineage is the same as its concept in penance; adultery for which one of the essential conditions is the man penis entering into the woman uterus. From the custom lineage concept the Islamic legislator just serves the lineage results from this concept as illegal and in the other cases, he serves the lineage results from it as legal.

The conditions of assignment and privacy in gamete donation:

The lineage of children resulting from gamete donation

1. Matrilineal lineage in sperm donate to the married woman:

The alien sperm is injected to the married woman vulva or to an unmarried woman's.

To lineage in sperm injecting to the married woman, there have been given several probabilities and opinions: 


\subsection{Assignment to the Inoculated Woman's Husband}

The believers to this opinion have reasons in detail as follow:

First reason: The fresh rule, referents to it divide to three groups and each has its own reasoning. One group has considered the mere marriage with the woman to her the intercourse is possible and sufficient to assign the child. Most Sunni jurisprudents have such adultery belief.

The second group considered the intercourse with woman as the condition in addition to marry, but after intercourse, carrying by any way, even by adultery or inoculation is assigned to the husband. Some Sunni and Shiite jurisprudents believe this.

The third group considers the intercourse the only way to reach semen to the woman uterus, so the assignment condition is to enter or ejaculate the husband semen to the wife uterus. In this discussion, as there is a doubt after husband intercourse, the Fresh (remarry) provision is imposed. Most Shiite jurisprudents believe this (of course by emphasizing doing intercourse).

Third reason: the essential interests of life, such as protecting lineage, and also moral, social and psychological interests.

\subsection{Assign to the Owner of Sperm}

This is also the dominated opinion. Macramé Shirazi (2008) assign it to the owner of sperm. Referring to the verses in Forghan, Dhār, Sade, Nil, Mom noon, Zama, Target, Ghyama, and adultery tradition of Mohammed bin Moslem, adultery baby results from sperm whether the owner of sperm be aware of the inoculation or not, is assigned to the owner of sperm; as the embryo creates from the man sperm and the woman ovule and the other elements lead to the embryo development.

\subsection{In the Adultery Sentence and Non-Assignment to None of the Man-Woman Parties}

Some of the Sunni jurisprudents tend to this idea and believe that we should consider it in the woman sentence (Khaledmansoor, 2008).

\subsection{Details between Knowledge and Awareness with Ignorance and Mistake}

Most Shiite jurisprudents and lawyers have such an opinion (Nazari, 2010). The civil law also confirms this theory about adultery in cases $1158-1167$ and 884 .

This group's reasoning is that if both the owners of sperm and ovule know that materials and parts of their genitals will be exploited in an alien inoculation and both with full awareness and authority prepare themselves to do such a thing, so in civil law and other rules we have no explicit wording and also in jurisprudence, if some traditions presented ( such as setting the sperm within the alien woman uterus, imposing sperm at non-religious position and so on ....) relates to the allowance or prohibition of the issue not the circumstances warrant and its legal state. Whereby, it seems from the method legislator has arranged for the assignment, the normal intercourse of the alien man and woman has no attributes to reject or prove the lineage, but the measure is the emergence of embryo from both an alien man and a woman sperm and ovule. Though the article 1167 of the civil law and the adultery evidence in jurisprudence don't contain it, but the measure of these two articles is certainly prevalent, so it can't be assigned to the owner of sperm, because it is the sentence of adultery.

But if man and woman don't know or the sentence has been misleading to them and a child burn from their sperm, using the articles 884, 1165, 1166 of the civil law and also revision of the manta of Wada reason to the doubt in jurisprudence, its sentence can be derived. Our discussion is the sentence of Wada to doubt and the child lineage in this legal manner is assigned to anybody who had not knew or has been wrong.

Practically, this sentence is possible that semen or ovule of a person is taken to do a test or conduct a genetic-scientific study or the human parts of body simulation, and then inject it to another woman. In this way, because this theory has no knowledge, attention or intention, the sentence of adultery is not imposed and it is condemned to the sentence of doubt. This reasoning can be criticized as follow:

Firstly, knowledge and ignorance are ineffective in circumstances warrants and person's legal states. Secondly, in natural, evolutional and even custom reasons the legal and circumstance warrants deserve explanation independently, and they are not abstracted from penal or obligatory warrants. Thirdly, despite the acceptance of non-relevancy of the intercourse between man and woman, the revision of manta and the discovery of the warrant original reason aren't possible easily. If this group mean the possibility of discovering the measure and the judgment of sentence, it should be said that the sentence measure cannot generalizes the sentence to other typical issues; especially when there is a fault in similarity between artificial inoculations with adultery.

Fourth, the child interests require that the given child is not deprived to have an identity and assignment; in particular, actors to artificial inoculation have no ill will and they have done this just to treat their infertility.

\subsection{The Assignment to Applicants and the Suppliers of Sperm}

Most rules and lawyers in west support this theory; such as England, France, most parts of the United States and Australia (Nazari, 2010).

The correct theory is the theory of the child assignment to the owner of sperm that is confirmed by the Islamic legislator and jurisprudence, legal and medical analysis. Certainly, the Islamic legislator follows the jurisprudents popular theory has preferred the second idea in the issue of children lineage born by intercourse and legally until the arrangement of the new rule, that will be applicable. Nevertheless, as in the issue there is no intercourse and the adultery has not occurred. Regarding the presented analysis the given child is legal and he is assigned to the owners of sperm. Since the measure is the law appearance and the child interest. 


\section{Matrilineal Lineage in Sperm Donation about a Bachelor Woman}

If a woman, who has been inoculated, has no husband, the other ideas can be examined about her except the first one.

\subsection{The Metronymic in Sperm Donation}

About the metronymic of the child born from the alien sperm it can be said that since the woman uterus was belong to them and the carrying and delivery have been done by themselves, based on all fundamentals, the owner of uterus is served as the mother, except an idea which distinguishes between the knowledge and ignorance. It seems that in that situation she is served as the mother too and if regards the appearance of the article 1167 of the civil law , she is served as the mother by knowledge too, unless we don't consider its measure, as the owners of this theory do it, but in that state it also seems that it is incorrect. On the other hand, in this way of fertilization, sperm is taken from an alien woman but she is the owner of uterus and also she has passed the pregnancy, embryo carrying and birth periods, so regarding the jurisprudents ideas there is no doubt in her metronymic .

\subsection{Matrilineal of the Child Results from Sperm Donation}

According to the tradition and Islam and also based on the dominated custom in most parts of the world, a woman cannot has more than one husband and this is because the generation integration would be prevented and based on it the inoculation with the alien man sperm is certainly incorrect. Apparently there is no other religious solution for it.

But in another case, in the legal law, man can take three permanent wife than one and also he can take temporary wife infinitely, so it can conclude that even if we consider the inoculation with the alien woman sperm illegal, a legal solution can be assumed for it and that is if a woman who donates the sperm is not exposed to marriage barriers, she can marry the man who is the sperm receiver woman's husband permanently or temporary and the act of embryo donation occurs legally and practically.

About the matrilineal of the child born in this way, there can assume some possibilities:

\subsection{Assignment to the Owner of Sperm who is the Inoculated Woman's Husband}

Regarding the above mentioned fundamentals in the first assumption (the adequacy of marriage or by intercourse condition or by the measure of ejaculation of the semen into the woman uterus) it can be said that the husband, has not committed an illegal action and the child also has been emerged from his sperm so according to the fresh rule, the child is assigned to him.

\subsection{Non-Assignment to the Inoculated Woman's Husband}

Because the measure of assigning the child to the husband is to combine his sperm with his wife's ovule, not the alien woman ovule, as the child has been born by an inherent illegal method, it is adultery and the child doesn't assign to him.

\subsection{Detail between the Husband Knowledge and Awareness of the Embryo Culture and between the Unawareness or his Mistake}

Based on the mentioned reasons the correct idea is the first one. It is noticeable that in the assumption, because the man intercourses with his wife based on the Sunni jurisprudents theory and Ayatollah Hakim, the child is assigned to the husband. Now, if he doesn't do intercourse according to Hakim theory the child is not assigned to the husband, but according to the Sunni jurisprudents, the child is assigned to the husband, from the civil law view based on the article 1158,1167 , it is assigned to the husband and if we consider the civil law spirit and measure - according to the third group opinion-regarding the measure of the articles $884,1159,1160,1165,1166,1167$, only in the lack of awareness or mistake, the child is assigned to him. Judicially it seems that the measure is the law appearance and it is more adjusted with the child interest.

\section{The Maternal lineage of the Child Results from Embryo Donation}

The child results from embryo donation is assigned to the owner of embryo based on the selected idea in this research, though the mentioned possibilities in the issue of transferring the embryo are also expressed here. If the owner of embryo is unknown, the child is served as the snapshot and if her embryo has been replaced by the owner of the embryo uterus or the knowledge to privacy is not existed, the child is assigned to the wife.

Accordingly, Sane'ie (2006) has considered the man sperm fusion with another woman ovule outside and its inoculation to the wife or the given or the third woman possible because neither it is adultery nor entering the semen into the alien woman's uterus.

Khamene'ie (2002) has replied that the given action is allowed by itself.

From Khamene'ie (2002) response that is" its assignment to the owner of uterus has problem so the legal sentences about the lineage should be followed" it is noted that certainly the child is assigned to the embryo donor and inherits her and also if he is a boy, she will be his confident, but about the assignment to the embryo receiver they hadn't have a certain opinion but as it comes because the child will born from her uterus and feed by her, based on the "consented" sentences, she is served as the child "consented" mother and the lineage problem will be solved. Ayatollah Sane also has this idea and believed that the ovum owner woman to whom the embryo is not belongs, is not served as the mother and they stated that by "consented" and accomplishing other conditions of "consented", she is served as the "consented" mother.

Therefore all the child sentences with his father are in sentences but with mother who have delivered him if the 
conditions of "consented" only the sentences of the "consented" mother are in sentences and the other sentences with the mother or the embryo owner will be in sentence and based on the cases will be presented next about the embryo donation.

\section{Privacy and Marriage in Embryo Donation}

\subsection{The State of Embryo Donation}

In the civil law, the marriage with the "consented", casual and relational terms has been banned to some degrees. In the state of embryo donation such a special situation is dominated that separated it from other assumptions. This state is the interference of two women to produce one generation. The main question is that which one has a real and actual lineage with the child and what about the other position?

The answer to the first part of the question was expressed at the previous section and it was proved that the owner of ovule is the mother. Here we examine the second part that is: what is the role of the owner of ovule? Is it possible to serve her the "consented" mother? Does her fostering establish the privacy?

Regardless of the theories that consider the owner of ovule as the consanguineous mother, according to the theories that consider the owner of ovule as the consanguineous mother, there are various theories regarding the owner of uterus:

1. Some jurisprudents and Islamic lawyers predict no special sentence between her and the given child, unless after birth, the owner of ovule foster him and the "consented" sentences accomplish, as they consider her uterus the only capacity to develop embryo. Some other jurisprudents, by accepting the above issue, say that: if the owner of ovule can't be the "consented" mother, it is better that she will be confident to the child, as she can feed him, and she would transforms him to a complete embryo who has the human soul.he can feed him, and transforms him to a the c ovum owner cant be the Rezai mother, the oved that the owner of o or the vulve

2. Some other jurisprudents have served her as the "consented" mother certainly and believe that there is a privacy between her and the child.

Medically, the owner of ovule doesn't interfere in the embryo generation, but has a broad role than a capacity or feeder for the embryo. Nevertheless, this amount of medical information about the uterus role doesn't change the custom decision about the maternal state. Because in spite of the uterus various roles, the embryo is accompanied with the genetic contents of the sperm and embryo owner and has a different system of the owner of ovule structure and is served as an another external object from which the uterus only prevents its repel.

By these, based on the unity of measure or the priority of concept, the "consented" closeness sentence to such a child is applicable. In traditions and jurisprudence terms, the development of meat and bone can be the provision to accomplish the confident issue. From the traditions, it is inferred that the milk is effective to determine the title of fatherhood and motherhood and these effects are not just the pure legal contracts, but the sentence shows an external topic that actually there is a kind of cause and effect, especially 3 kinds of measure: The number of fostering during a day or 15 times sequentially or the development of the meat and bone. Thus, if each measure is accomplished the privacy will accomplish, in addition, it doesn't prohibit the jurisprudent commitment of the privacy between the child and the owner of ovule, because when fostering 15 times daily, lead to the privacy, the development of the embryo in 9 months within uterus in the former manner lead to the confident and prohibition of the marriage.

It seems that from these two perspectives the above deduction is not acceptable:

1. Jurisprudent view; firstly, this is like comparison, even if the elements of comparison is completed, because the origin of physical development in "consented" is not the woman body internal materials, unless it is proved that the milk is just the body internal completed materials; secondly, the legislator doesn't consider the mere development from the milk sufficient to issue the privacy, but considers some other conditions such that milk has been emerged from a legal relationship; fostering be in a form of sucking and....so if the child develops just by fostering without devotional conditions it's not lead to privacy.

2. From the civil law perspective: articles 1045, 1046, 1047 consider3 elements relate to the closeness origin and the marriage barriers: consanguinity, causal state and "consented". None is adjustable with its conditions on the discussed topic. Thus "consented" has subjectivity and privacy. With all these justifications, the ethical, psychology and social-historical beliefs prohibit the child to marry the owner of ovule, but it assumes a double privacy between them, as the public ethical avoid it severely and considers it stronger than "consented" relation; if a day of "consented" in a woman arms makes her a mother, it will be reasonable that his development within her uterus to 9 months, lead to privacy in marriage. From this, the second question's answer is revealed, because in some kinds of the embryo transferring in which the embryo is made up of the genetic materials and the second wife uterus has been transferred, it causes privacy, but transferring to an alien woman uterus and her pregnancy makes the milk to cause the confident doubtful; particularly that the origin is the non-closeness (Meshkati, 2008).

Regarding that the intercourse is not the case, the ultimate development that can be considered is that whenever the embryo resulted from a combination of the couple sperm and ovule and it has been transferred to another woman uterus, it can cause the issue of privacy, as the given milk has been made legally the "consented" privacy is made but the milk 
resulted from a combination of two alien genetic materials, its transferring to an alien uterus or the owner of ovule doesn't cause the issue of privacy, even in the presence of the execution conditions, but if we consider the combination legal, even to produce generation it is necessary to follow the executed and forming conditions. In any case, judicially the measure is the article 1045 and the subsequent articles of the civil law.

In article 1046 from the civil law it is stated that consented lineage is in the sentence of relative lineage from the marriage privacy view and the article 1047 brings the consented lineage in line with relative. Surely, it should be noted that consented just lead to the issue of privacy and it is a marriage barrier but in other cases doesn't impose any law or obligation.

\section{The Sperm Donation State}

About the girl privacy to a woman's husband who has received the sperm, most jurisprudents don't believe in privacy and only some consider it confident based on the lineage and stepdaughter relation with that woman.

\subsection{The Lineage of the Child Results from Embryo Donation}

The study of matrilineal of the child results from embryo donation. The holy jurisprudent confirms the lineage when he relies on the correct intercourse and the couple relation. Thus regarding the embryo formation from the combination of the man and woman sperms who donate the embryo, there is no doubt in assigning the formed embryo lineage.

Therefore it is certain that man without sperm has no consanguinity with the born child and the owner of sperm he will be the child father. If the owner of sperm be clear, all the legal and judicial traces such as heritage, guardianship and custody, alimony establishes between the owner of sperm and the child. Thus, as the man without sperm who is the donated embryo receiver woman's husband, he has no consanguinity with the born child; if the child is adultery girl he is the man stepdaughter without sperm. Medically, the origin of the child emergence from the father is the sperm exists in the semen. In most verses of the Quran also this topic has been expressed for example:

1. Forghan, verse 54:

And he is who created a man from liquid and set a lineage for him and your God is always powerful.

"liquid" is the embryo liquid from which all mans create by the God power, when the man sperm which is floated on the liquid combines with the woman ovule the first sign of the man's life is emerges that is the first man living cell .

\section{Dahr verse 2:}

And we created the man from the mixed sperm to examine him and makes him clear-sight and hearing.

The verse indicates how the man was created.

3. Sajdeh 7:

As someone who has made everything beautiful created and began the creation of man from clay:

Sajde 8: then he set his generation from low liquid abstract.

4. Taregh 7:

Who is comes out of the man solid and the woman breast bones.

" solid means hard and it belongs to man, in that semen exits from the man's back that is the woman breast bones and each bone is called the Soil ". Here Quran points to one of the two parts of the sperm that is man sperm and is tangible for all, "solid" and "combining" means the back and front parts of the man respectively, as the man sperm liquid exits from these two.

Solid refers to the men blood and "soils" to the women's. Since men are the symbol of power and the women are the symbol of fragility, so the verse points to the combination of man -woman's sperms.

Regarding the verses and traditions, it is true that this manner is the summation of the ethical mentioned cases; both from the embryo emergence origin and also the transfer to the woman uterus who is the owner of sperm and alien ovule. However, the child is assigned to the owner of sperm and ovule and the uterus owner is the child confident.

To determine the child matrilineal state, most jurisprudents consider father as the owner of sperm. Thus most jurisprudents believe that the man who is the owner of sperm is the child father resulted from embryo donation and about the mother they believe that the woman ovule is the child root and origin.

\subsection{The Study of Metronomic of the Child Results from Embryo Donation}

Now the question is that by embryo donation is the child's mother the owner of sperm or the owner of uterus?

Various opinions have been presented in this context:

1. The owner of uterus is the child 's mother:

Araki (1998) says that: "the sperm from the owner of ovule induces the owner of uterus that the latter is the recent part of the absolute cause of the child birth. According to Khoie (2000), if a woman places an alien man sperm in her uterus she is guilty but the child belongs to her and the owner of sperm and if the child be a girl, the owner of sperm can't marries her.

This group's reasons are these verses in which God defines the mother as the one who carries and delivers and tolerates the pregnancy difficulties. Thus the opposite concept is that if a woman doesn't carry and deliver and also doesn't tolerate the pregnancy difficulties, she is not the mother. Rationally, the child isn't just results from the woman 's ovule and the inherited attributes , but the child and generally the human is the consequence of his surrounding environment, especially when the embryo is cling to the uterus wall and all his existence affected by the uterus.

2. The owners of the ovule and uterus both are the child mothers:

Through verses and traditions the mother is the owner of ovule or the owner of uterus; but regarding their undeniable roles in the child creation, the assignment of the term 
"mother" to both of them is possible.

Mosavi Ardabili (1996) has stated that: if an embryo transferred to the uterus of another woman when it is sperm or suspended or chew or after blowing the soul into it and it develops within that uterus, both women are his mothers and this child is served as double-maternal"

3. None of the owners of ovule and uterus are the child mother:

Some consider the assignment of the child to the mother caused by two factors:

3.1. The child's inheritance and evolutional relation with the mother which caused by ovule.

3.2. The carrying, delivery and custody relations which occurs by uterus. So if the ovule belongs to the woman who accepts no responsibility and is carrying another woman embryo, the two factors do not exist for both the owners of ovule and uterus and none of them serve as mother.

4. The owners of ovule and uterus are the child's consented mothers:

According to this theory, though they can't be the consanguine mothers, but the child has a relation with both the owner of ovule and uterus and they can be his "consented" mothers; because both of them incorporate in the child emergence.

5. The owner of ovule is the child mother:

The measure of motherhood in custom is the same as fatherhood. Custom serves a woman as the mother who has incorporated in the first stage of the embryo creation and emergence. That woman is the owner of ovule nobody else; as her ovule has interfered in the first stage of the embryo emergence and the embryo sperm has come out of her ovule combining with sperm. After this stage, the physical development has no role except continuing the child growth.

It is inferred that the child results from the embryo donation relate to the owner of ovule and uterus undoubtedly; but the significant point is that whether the ovule is the measure for the child and maternal relation or the uterus and child delivery?

In medical science it has been proved that the origin of embryo emergence from mother area is the woman ovule. But in the past custom the way of distinguishing the child emergence has been delivery. But now it has been proved scientifically that the embryo sperm is made by the released ovule from the woman ovary. Thus the indication of delivery assignment is not absolute; but the legislator has kept its indication to keep the family's peace. So, if that custom be certain in a special case that a woman is infertile, is she a mother just because she can carry and deliver? while in contrast that is the infertile woman who is not able to carry or delivery because of some reasons such as the mother death, the premature embryo or the risk for one of the child or the mother and the delivery performs by surgery and the child develops in the artificial uterus under the special cares, the custom believes that the owner of uterus, nevertheless she did not deliver the child, she is the child actual mother and its reason is that custom considers the origin of the child emergence other than carrying or delivery.
There are some verses in Quran that confirm this:

1. Najm 46: "from an embryo when it is poured"

Here "sperm" is apparently the man sperm; as the woman sperm at that time was not tangible. the adverb" when poured" means until it is not placed at its position there is no creation.

2. Mom noon 14:

Then we transformed the sperm to the suspended clot and then made the chew as bones, then covered that bones with meat, then created the embryo in another creation. Praise God who is the best creator. Just as sperm from the father back placed into the mother uterus, the angles attended to shape it and they say "oh God we should make this sperm a girl or a boy whatever belongs to providence ... because the sperm set into the woman uterus it turns to the blood during 40 days and ..."

It can conclude that regarding that the embryo is within the mother uterus during 9 months and feeds from her meat and body, in this area, "consented" sentences can help and the born child can be served as the pseudo-"consented" child for the uterus owner woman and accordingly he is the uterus owner woman 's husband child, but in fact the actual lineage of the child belongs to the owner of sperm and ovule but as they have disclaimed their embryo and donated their embryo ,so they cannot claim the child assignment . However there exists no clarity in law and this is one of the significant drawbacks of the above law by itself.

3. privacy in the embryo donation :

If the born child resulted from the boy embryo donation, it prohibits him to marry the owner of uterus or the ovule is similar to the ovule donation; but if the born child is a girl, the state of her prohibition to marry the owner of uterus's husband (the applicant father) and the owner of sperm makes new state which have had no background in the world of law. In the presence of fresh indication, the child is assigned to the owner of sperm and he is as the applicant father, so the applicant father becomes the child's legal father. As a result the marriage between the girl and the applicant father will be prohibited. But another important case is the marriage prohibited for the girl with the owner of sperm by his sperm the embryo transferred to the mother uterus has formed.

What has been mentioned about the indication of Fresh and the embryo donation state is in sentence to prove that, while in this step the child has born from the donor man's sperm such that the embryo has transferred to the applicant mother uterus and as a result the child has been emerged from it, it has been made of the combination of the donated ovule with the donor man's sperm. Therefore referring to the available lineage at the prove step, the sentence is that the born girl is prohibited to marry the owner of sperm man from his sperm the child is emerged, besides the indication of Fresh is still maintained. The other form is the invalidity of the Fresh indication by bringing a complaint relates to the child lineage from the sperm donor. Thus the child is assigned to the sperm and the child consanguine relation with the applicant father is lost. In this situation the owner of sperm is the legal father for the born child because of the fatherhood relation between them, based on the article 1045 of the civil law the child marriage (girl) 
with the sperm donor man prohibited. But another significant issue is that if this girl marries the applicant father who according to the Fresh indication he has been served as her father once and now by dropping the indication, the fatherhood relation is dissolved and this relation is no more established between them. The civil law is silent about the born girl marriage with the applicant father who lost his fatherhood position by the invalidity of the Fresh indication while he has been served her father once." On one hand, the prohibition of the person marriages with each other is an exception that relates to the social customs and religious traditions closely and it is difficult to develop it. In civil law also the consanguine, causal and "consented" relations are three marriage's barriers, that isn't different from legal provisions in this case . So how can account for the above mentioned situation as a marriage barrier that is resulted from the embryo donation state while the nature of the embryo donation state is not clear by law?

A couple who tends to have baby using the inoculation and embryo donation and brings a child into the family, they should look him up as their child and think about his happiness The lovemaking temptation with such a creature turns the family into a sensual environment and endangers the public sentence undoubtedly. " thus the public ethical cannot accept someone marriage who have been in place of the father and child ".

Just this is imaginable about a boy and the applicant mother. If the owner of ovule accounts for his mother and we don't open "consented" closeness sentence about the marriage prohibition on the owner of uterus, the child identity relies on the delivery external event that is issued considering the marriage relation between the woman who did the delivery and the applicant father, so they are the child parents. Therefore it can be said that to issue the child identity card with the applicant father and mother names as the child parents especially with the father last name for the born girl of the embryo donation, is an allusion that once the law has considered the child as a member of a family composed of the applicant parents as the child parents.

It seems that with the reasoning that once "the applicant father and the girl" or " the applicant mother and the boy" has been considered as the father and daughter or the mother and son by law and according to the article 1047 of the civil law, the motherhood and fatherhood relations lead to the permanent privacy and the marriage between child and the parents is prohibited permanently, the sentence to permanently prohibit the applicant father and mother marriage with the born girl and boy resulted from embryo donation can be issued. This conclusion is matched with the civil law fair and soul about the marriage privacy and also it has social and ethical benefits.

Thus it seems that the applicant parent's marriage with the born child by the embryo donation is prohibited permanently. This sentence can be applied for the applicant parent's probable children regarding the born child as adultery result of embryo donation, but generalizing this privacy to the applicant parent's other relatives is not firm public ethics (assuming they are not considered as the child parents or the applicant father has been considered as the child father once but now the consanguine relation has been dissolved because of the Fresh indication dropping or the applicant mother who has delivered the child is not considered as the child 's "consented" mother) and on the other hand the persons marriage with each other prohibition is an exceptional sentence its items can't be developed. The civil law only accounts for "consented", causal and consanguine relations as the marriage barriers. With the due attention to the civil law content there exists no reason for the marriage privacy between the child born by embryo donation with the applicant parent's other relatives assuming that they are not the child legal parents or the applicant father has been served as the child father once but now the lineage is dissolved because of the Fresh indication dropping or the applicant mother who has delivered the child is not served as the child "consented" mother. The imposition of the marriage prohibition to other relatives in this case requires the legislator's special sentence.

\section{Conclusions and Recommendations}

The full assignment of the child to the applicant parents is not accepted in Iran law. The law in Iran is also silent about the marriage prohibition. If we accept the child assignment to the applicant man and woman, the marriage prohibition with the close relatives will be one of its consequences. With the law silence and presenting some of the lineage effects, it is difficult to accept this idea. But the child, family and public ethic require that this person be prohibited to marry the applicant man and woman or their close relatives.

At the end of the research it can be concluded that embryo donation is allowed regarding most of the jurisprudent opinions. Accordingly, legislators have legislated the law. Passing the law, the way of embryo donation to the infertile couples at 1382 and its applicable procedure at 1383, it seems that no longer there exists a prohibition in Iran law and the law accepts the uterus outside inoculation methods from legal couples to the applicants. Referring the jurisprudence books and sources views are seen in this area. But considering the novelty of this issue, the artificial inoculation or embryo and gamete donation is a challenging issue and many jurisprudents have discussed it. The classic jurisprudence assign the embryo to the owners of sperm and ovule and if we use this measure as the criteria, a consanguine relation is made between the born child and the gamete owners and thereby all its effects occur between them such as guardianship, custody and marriage privacy and heritage. But in the contemporary jurisprudence some jurisprudents who don't consider the basis of the topic illegal, present different views: 1- Some jurisprudents affected by the traditional theory believe in the father and motherhood lineage between the gamete owners and the child, they establish a lineage and privacy in marriage between them. 2 . Some other jurisprudents believe that the gamete owners have disclaimed the embryo by donating it and they will have no right about that embryo or child, from now on, the donation receivers have rights to the child and they believe in caution 
about the privacy in marriage. This class of privacy in marriage establishes the custody and alimony between the child and donation receivers and in the heritage context this relation is assign to the child and the uterus owner woman and they pronounced that the child and the uterus owner's husband don't inherit each other. 3- The third group of jurisprudents considers the lineage measure also the gamete ownership and delivery such that they establish the privacy in marriage between gamete owners from one hand and the child on the other hand.

Therefore the legal parents of the child born from embryo and gamete donation are the real owners of the sperm and ovule forming the embryo. About privacy in donating the child resulted from embryo donation with the sperm and owner of ovules establishes the privacy and jurisprudents have pronounced the privacy of the child with the owner of uterus and served her as the child's real mother. Accordingly it can be said that the resulted child is the owner of uterus and her husband's and is also the sperm and owner of ovules child. But considering Ayatollah Sane opinion it is inferred that as the owners of gamete of the resulted embryo from their sperm and ovule have disclaimed it, so the resulted child is assign to the uterus owner and her husband. It should be noted that in fact the owner of uterus husband is not the child real father but because of his wife's motherhood to the child he is also the child father not in the real meaning but virtually. Indeed if the resulted child is a girl, she is his stepdaughter and is confident to him.

At the end of the research, the authors would like to recommend the following:

1. What is obtained from this research and other identical studies is that the child lineage is assigned to the owners of sperm and ovule. There is no discrepancy in the artificial inoculation methods. But in other methods such as ovule and gamete donation it is recommended to use the ovary transplant for the woman or the testis transplant for the man to solve the child lineage problem.

2. Stating medical problems in this context is significant. Some jurisprudents have not been satisfied about some actions adequately, so expressing medical problems not only can satisfy them but also lead scholars to various aspects of the topic.

3. As the embryo donation is allowed by jurisprudents in one form that is the ovule donation, so it is better for the legislator to amend the mentioned cases and legislate special provisions in the way of embryo donating to the infertile couples, the way of donating ovule in that provision or as another independent provision.

\section{References}

[1] Babai AA. 2003. Sample interpretation selection. Tehran: Islamic bookstore.

[2] Borojerdi SMI. 1987. Jami Tafsir, Tehran: Sadr Publications.

[3] Gharashi SAA. 1998. Ahsan al Hadis tafsir. Tehran: Besat Institute.

[4] Gheraati M. 2004. Nor tafsir. Tehran: The cultural center of lessons of Koran.

[5] Ghasemzadeh, M. 2007. Main conditions of curing un productivity using gamete and chrysalis. PAYESH, 6 (4). 419-437.

[6] Hor-Ameli MH. 2000.Vasayel al Shiite , $15^{\text {th }}$ edition. Tehran: Maktab al Islamic.

[7] Vasayel al Shiite (1 $7^{\text {th }}$ editions), Dar al Ahya altras alarabi. Beirut, al tras and al Ahya Al-beit institute, p.1424.

[8] Husseini-Hamedani SMH. 1983. Bright lights. Tehran: Lotfi Publications.

[9] Khamene'ie SA.2002. Practical laws of Islam. Tehran: Alhoda international publication.

[10] Khani R, Heshmat-Allah R .1993. Bayan al Sadat fi Maghamat Akebadat Translation. Tehran: PNUmat Akebadat Translation,tehran, ond p, PUB LICATION.

[11] Khaledmansoor, M. 2008. Islamic jurisprudence. Majma Fegh, 2 (2), 317-321.

[12] Khooie, SAG. 2000. Shiite issues, transactions referendum. Tehran: Institute to recover Imam Khomeini's works.

[13] Khooi- Tabrizi MH. 1996. Path of deliverance in referendum answers, polls collection, $1^{\text {st }}$ edition, Tehran.

[14] Mohagheghdamad, M. 1998. Jurisprudence and law of embryo transfer. Tehran: Jahade Daneshgahi Publications.

[15] Motarjeman. 1997. Hedayat tafsir. Mashhad: Razavi Ghods Research Center.

[16] Makarem-Shirazi N. 2008. New polls. Tehran: Besat Institute

[17] Merghati, ST. 2007. Children's right in gamete donation. PAYESH, 6(4), 347-354.

[18] Meshkati, Sh. 2008. Donation of gamete and embryo in Iranian law. Unpublished master's thesis. Tehran, Iran.

[19] Moosavi Ardabili ,1996. seed Abdol Karim , Tozih al Masael treaties.

[20] Nazari A. 2010. The jurisprudential study of the child lineage results from artificial inoculation. Journal of Jurisprudence and History of Civilization, 23 (2).

[21] Sane'ie Y. 2007. The collection of polls issues, second edition. Qom: Meysam Tamar .

[22] Tabatabai SMH. 1996. The balance in the interpretation of Koran. Beirut: Scientific Publication. 